Working Papers in Economics

Death as a measure of duration of conflict

Ayla Oğuş, İzmir University of Economics Sacit Hadi Akdede, Adnan Menderes University

Working Paper \# 08/04

May 2008

Izmir University of Economics

Department of Economics

Sakarya Cad. No:156

35330 Balçova Izmir

Turkey 
Working Paper \# 08/04

\title{
Death as a measure of duration of conflict
}

\begin{abstract}
This paper argues that the number of deaths in a conflict can be a measure of duration and demonstrates that there are information gains to this approach. The well-known conflict database of International Peace Research Institute is compared with the database of Center for Systemic Peace which includes data on the number of deaths in addition to length of conflict. There are differences in the two datasets. The number and distribution of conflicts vary however duration analysis yields results that are robust over datasets. We also show that the number of deaths, as a measure of duration, challenges some of the results based on the number of years as a measure of duration. We can also argue that economic integration coincides with shorter duration of conflicts in terms of both deaths and years. International conflicts have a shorter life and have fewer deaths than domestic conflicts. Geographic or ethnic characteristics of conflicts are not robust over datasets nor over measure of duration.
\end{abstract}

Key Words: Duration models; violence and wars

JEL Classification: C41; H56, N40.

\section{Ayla Ogus}

Department of Economics

İzmir University of Economics

Izmir, Turkey 35330

Email: ayla.ogus@ieu.edu.tr

\section{Sacit Hadi Akdede}

Nazilli İ̈BF

Adnan Menderes University

Sümer Kampüsü, Nazilli, Aydın Turkey

Email:shakdede@adu.edu.tr 


\section{Introduction}

This paper empirically investigates the duration of conflict as recorded, defined and classified by the Center for Systemic Peace (CSP) and International Peace Research Institute (PRIO). Duration is measured by both the total number of deaths and the number of years from conflict to peace. The number of deaths is the human cost of the conflict and is also a measure of intensity. Intensity can be a measure of duration since the sides of the conflict can be expected to work towards ending the conflict as human casualties accumulate. It is possible that the sides of the conflict play a game to have the other side declare defeat by announcing peace or any kind of arrangement to end the conflict. We borrow this concept from cultural economics and show that it yields interesting results. This paper, however, is not modeling the micro behavioral dynamics of conflict. It is mostly intended to set the stylized facts about whether different types of conflicts have different duration in terms of intensity.

During the last fifteen years, world trade as a percentage of GDP has increased significantly, people are more mobile within and across countries to find better jobs, and they produce more goods and services compared to earlier periods. Economically, transaction costs are getting lower and the world is getting more integrated. This economic integration of the world is not exactly synchronized with political integration since there have been many secessionist, separatist and nationalistic movements, violence and wars in the world during the 
process of economic integration as our data section analyzes; in the 1990s, compared to the previous four decades, the world has seen more violence. However, the duration of violence in terms of both the number of deaths and years was shorter in the 1990s. Therefore, the economic integration era has seen more political disintegrations with lower intensity. Economic integration and political disintegration have been investigated in a different context in the literature (Alesina et al., 2000; Alesina and Spolaore, 1997). That line of research is about the endogeneous determination of the number and size of countries and governments and international trade. This paper, however, is about the duration of political violence and wars and some of their determinants such as secessionist, separatist and nationalistic movements. These movements are also considered to be politically disintegrating actions with high human and economic costs but have not been studied to date. This is the main contribution of this paper. More specifically, this paper focuses on the following questions: Do we have a longer duration in terms of deaths and years in wars and political violence in the 1990s compared to the earlier period since the second half of the 1940s? Do different types of violence and war have significantly different durations in terms of deaths? For example, do international wars have more deaths than civil wars? Do civil wars have more deaths than civil violence episodes? Does ethnic violence have more deaths than civil violence? These questions are answered within the framework of duration models which is a novel approach to modeling the duration of political violence and war.

Political violence and wars have been investigated recently from different perspectives. For example, their connection with terrorist events is studied by 
Addison and Murshed, (2005), Krueger and Maleckova (2002), and Li and Schaub(2004). The relationship among ethnicity, conflict and civil wars has also been investigated (Sambanis, N.,1999; Easterly, 2000; Ellingsen, 2000; Fearon and David, 2001, Khazanov, 2005). Another line of research is connection with political variables such as democracy and their effects on violence and conflict (Mousseau, 2001; Minier,2003; Reynol-Querol, 2005). Quantitative and historical aspects of civil wars have also been studied (Sambanis, 2002; Elbadawi and Sambanis, 2001). All these studies investigate the causal connection among related variables. They are not specifically concerned about the duration of political violence and wars.

One of the few papers investigating the duration of civil wars is Collier et al.(2001). They study violent civil conflicts over the periods 1960-99 to analyze the duration of conflict. They estimate hazard functions based on behaviors of rebels and governments. They find that the duration of conflict is determined by a substantially different set of variables from those that determine the initiation of conflict. Notably, the duration of a conflict is substantially increased if the society is composed of a few large ethnic groups, if there is extensive forest cover, and if it commenced after 1980. None of these variables has any significant influence on the risk of conflict initiation. An implication is that the anticipated duration of conflict does not significantly influence the decision to rebel. In turn, this suggests that the initiation of rebellion is not closely related to the prospect of post-victory goals. Another paper in the same line of combining theory and empirics of civil wars is Elbadawi and Sambanis (2000). They argue that civil war occurrence and duration may be modeled as the result of a forecast error on 
the part of the rebels or the state with reference to each other's military capability. They state that unlike international wars, which are usually short-lived, civil wars are prolonged. According to the argument above, they explain that this would mean that either the rebels, or the government, are over-optimistic about their relative military capability, leading to errors in judgment that prolong wars. The duration of the war is basically determined by the ability of the rebel movement to remain intact, sustain itself, and avoid military defeat.

This paper estimates the duration of different types of conflict for two alternative measures of duration. It differs from the studies of Collier et al.(2001) and Elbadawi and Sambanis (2000) in terms of the duration and type of conflict. This paper analyzes the different types of conflict and violence such as ethnic violence, civil violence, civil war, international war, ethnic war, international violence, and independence, whereas Collier et al.(2001) and Elbadawi and Sambanis (2000) investigate the duration of only civil wars. This paper empirically analyzes the duration in terms of the number of deaths in addition to the number of years from war to peace, Collier et al.(2001) and Elbadawi and Sambanis (2000) analyze the duration in terms of time from war to peace. Also, this study uses a data set that has not been used in this manner before: the data set of Center for Systemic Peace (CSP).

Therefore, both in terms of methodology and the dataset used, this study is one of the very few empirical articles in the field. In this sense, this paper attempts to establish the stylized facts about the duration of various political violence and wars in terms of deaths and years. The paper develops as follows. The next section develops the methodology used in the paper. Section III gives 
the data sources and descriptive statistics. Section IV gives the results and the last section concludes the paper.

\section{Modelling duration of conflict}

This paper empirically investigates the duration of different types of conflicts to understand whether they have a different length of duration in terms of deaths and years. We employ duration models to analyze the factors that affect the duration of a given conflict. Duration models have been applied to a variety of economic problems such as length of unemployment, duration of strikes, interval between purchases and time to business failure to name a few.

Duration models analyze the length of time between the beginning of an event and its end. The origin of such models is in engineering where the lifetime of a component was of interest. Therefore, in the literature, the end of the event represents failure. Let the duration or length of time between the beginning and end of an event be a random variable T. Suppose $\mathrm{f}($.$) is the probability distribution$ for $\mathrm{T}$. Then cumulative probability $\mathrm{F}(\mathrm{t})$, where $\mathrm{t}$ is the realization of $\mathrm{T}$ represents the probability failure happens before $t$.

$$
F(t)=\int_{0}^{t} f(s) d s=\operatorname{Pr} o b(T \leq t)
$$

The probability that duration is at least $\mathrm{t}$ is given by the survival function $S(t)$.

$$
S(t)=1-F(t)=\operatorname{Pr} o b(T \geq t)
$$

If the length of an event has lasted until time t, what is the probability that it will end shortly at time $(\mathrm{t}+\Delta)$ ? The hazard rate, $\lambda(\mathrm{t})$ will answer this question. 


$$
\lambda(t)=\lim _{\Delta \rightarrow 0} \frac{\operatorname{Pr}(t \leq T \leq t+\Delta \mid T \geq t)}{\Delta}=\frac{f(t)}{S(t)}
$$

The hazard rate gives the rate at which failure occurs after duration $\mathrm{t}$, given that it has survived until $\mathrm{t}$.

The Weibull distribution is widely used in the literature to parametricize $\mathrm{F}(\mathrm{t})$. The Weibull distribution has two parameters $\theta$ and $\alpha$ such that

$$
\begin{gathered}
\mathrm{F}(\mathrm{t}, \theta, \alpha)=1-\exp \left(-(\theta \mathrm{t})^{\alpha}\right) . \text { Then } \\
S(t)=\exp \left(-(\theta t)^{\alpha}\right) \\
f(t)=\alpha \theta^{\alpha} \mathrm{t}^{\alpha-1} \exp \left(-(\theta t)^{\alpha}\right) \\
h(t)=\alpha \theta^{\alpha} \mathrm{t}^{\alpha-1} .
\end{gathered}
$$

For $\alpha<1$, the hazard is decreasing over $t$ and for $\alpha>1$ the hazard is increasing.

\section{Data}

The chief aim of this paper is to promote the number of deaths in a conflict as an alternative measure of duration of a conflict. The number of fatalities in a conflict is available in the dataset of Center for Systemic Peace (CSP) which became available in 2001. Since this dataset has not been employed in empirical work certainly not as ubiquitously as the PRIO dataset we will first compare and contrast the two datasets before proceeding with the duration analysis.

\section{CSP}

Major Episodes of Political Violence 1946-2006 compiled by Monty G. Marshall, Director, Center for Systemic Peace. The data set covers all wars and violence recorded, defined, and classified by the Center for Systemic Peace for the period from 1946 to the present. Duration is captured with both the intensity of the 
violence and war which is measured by the number of deaths in the violence and wars and the number of years from violence and war to peace. Our conflict data is taken from Major Episodes of Political Violence 1946-2005 of the Center for Systemic Peace (CSP). This data set classifies the political violence into seven different categories: international violence (IV), international war (IW), ethnic violence $(\mathbf{E V})$, ethnic war $(\mathbf{E W})$, civil violence $(\mathbf{C V})$, civil war $(\mathbf{C W})$, and independence movements $(\mathbf{N})$. In other words, the episode type is listed according to two character codes. The first character denotes either a (C)ivilintrastate involving rival political groups; $(\mathbf{E})$ thnic-intrastate involving the state agent and a distinct ethnic group; or (I)nternational event-interstate, usually two or more states, but may denote a distinct polity resisting foreign domination (colonialism). The second character connotes either an episode of (V)iolence-the use of instrumental violence without necessarily exclusive goals; (W)ar-violence between distinct, exclusive groups with the intent to impose a unilateral result to the contention; or $\mathrm{i}(\mathbf{N})$ dependence-an attempt to forcibly remove an existing foreign domination.

Descriptive statistics on the variables used in the empirical analysis are presented in Table 1. We employ two different measures of duration, namely number of deaths and length of conflict in years. The latter is admittedly a crude measure of duration. We use it to complement our results based on the number of deaths and to see if there is reason to believe determinants of conflict duration are sensitive to the way duration is measured.

One might be more inclined to think of duration as a time frame, however, when duration is analyzed, one is analyzing when an event ends. In that sense, the 
number of deaths is a valid framework in analyzing when a conflict ends. We opt to use number of deaths as a measure of duration following the literature on duration of cultural events. Simonoff and Ma (2003) and Maddison (2004) use the number of performances as a measure of duration in their analysis of duration of Broadway shows and Walls $(1997,1998)$ uses box office revenue as a measure of duration for the Hong Kong movie market. It is found that a one million dollar increase in box office revenue would increase the expected life length of a movie by about 2.5 times.

We have 271 conflicts between 1945 and 2004. The mean number of deaths in a conflict is 90,922 and the mean duration of a conflict is 5.84 years. The number of deaths in the conflict with the least human casualties is 200 and the biggest in terms of human cost amounts to 2 million deaths. Conflicts with the shortest duration in the sample are those that started and ended in the same year. We do not differentiate between say a conflict which lasted 2 months and one that lasted for 11 months. The duration for both of these conflicts would be zero but they would differ in terms of number of deaths, presumably with the one with that lasted only one month ending in fewer deaths than the one that lasted for eleven months. The conflict with the longest duration lasted for 56 years.

Table 3 presents the geographic distribution of conflicts. The majority of the conflicts have taken place in Asia. Africa is a close second with 77 out of 271 conflicts. Latin America, the Middle East and the rest of the world have experienced fewer conflicts. Most of the conflicts are what is classified as a civil violence by the CSP. There are 68 civil violence episodes, compared to 50 civil wars, and 45 each ethnic violence and wars. Independence movements are 
relatively few in number. The world has seen 13 independence movements since 1945. International violence episodes are 28 compared to 22 international wars. Notably, civil violence episodes are concentrated in Asia and Latin America and not Africa. Civil wars, ethnic violence and wars are heavily located in Asia and Africa, mirroring the distribution of total conflicts.

In Table 3, the mean number of deaths of different types of conflicts, i.e. the human cost, is provided. The heaviest human cost is of civil wars. The mean number of deaths in a civil war is around 257,000. Ethnic wars also result in large human casualties. The mean number of deaths in an ethnic war is around 150,000. International wars are relatively less costly: the mean number of deaths is 50,000 . Violence episodes, whether civil, ethnic or international, result in fewer deaths compared to wars. However, the CSP classification is not based on the number of deaths but rather the intent of the conflict.

The duration of a conflict in terms of the number of years presents a similar picture. Wars generally last longer than violence episodes. However, civil and ethnic violence episodes last longer on average than international wars. Ethnic wars have the greatest longevity with 12 years on average.

Table 4 demonstrates that in the globalization era, we see more conflicts than previous decades, hence economic integration coincides with political disintegration. In the table, we excluded the conflicts that started after 2000 since most of these conflicts are censored and therefore, would not give a true measure of duration. In the nineties, conflicts end sooner and involve fewer casualties. The mean duration in the nineties in 1.89 years compared to 9.13 years in the sixties and 8.31 in the seventies. Conflicts in the fifties were very intense. Even though 
the mean duration is not so long, 4.38 years, the average number of deaths was very high, at around 160,000. By the same token, conflicts in the eighties were intense compared to conflicts in the sixties which lasted longer and resulted in fewer deaths. Specifically, conflicts in the sixties lasted for 9.13 years on average and caused around 53,000 deaths. Conflicts in the eighties lasted for 5.93 years and caused around 65,000 deaths.

\section{PRIO}

This data is from the third version of the Armed Conflict Dataset developed and maintained by Department of Peace and Conflict Studies at Uppsala University and the Centre for the Study of Civil War at the International Peace Research Institute. Armed Conflict Dataset, a joint project between the Department of Peace and Conflict Studies, Uppsala University and the Centre for the Study of Civil War at the International Peace Research Institute, Oslo (PRIO). The dataset was first presented in Gleditsch, Wallensteen, Eriksson, Sollenberg \& Strand(2002),

The dataset codes years of conflict and conflict is defined as more than 25 battle related deaths in a year. If a conflict between the same parties for the same reason is repeated that is coded as a subconflict. In our analysis, the unit of measurement is a subconflict. There have been 331 such conflicts since 1946. 161 of these conflicts do not have any subconflicts. 44 consist of two subconflicts, 18 of three and 3 each of four and five subconflicts. When we talk about duration we are referring to the duration of the subconflict as defined by the number of consecutive years. When conflict subdues, i.e. ceases to cause more than 25 deaths per year, we consider it to be over. 
The Armed Conflict Database defines the intensity of the conflict in three categories. The intensity of the conflict is minor if the total number of deaths is less than 1000. The conflict is considered to be war if the number of deaths is greater than 1000 per year. The Armed Conflict Database also defines an intermediate category of more than 25 battle-related deaths per year and a total conflict history of more than 1000 battle-related deaths, but fewer than 1,000 per year. Based on this categorization, we investigate how the duration of wars differs from less intense conflicts.

We also distinguish between international and local conflicts. International conflicts include those between two or more governments or between a government and a group outside the territory of the government. Four types of conflict are defined in the Armed Conflict Database: Extrasystemic armed conflicts that occur between a state and a non-state group outside its own territory; Interstate armed conflicts occur between two or more states; Internal armed conflict occurs between the government of a state and internal opposition groups without intervention from other states; Internationalized internal armed conflict occurs between the government of a state and internal opposition groups with intervention from other states. We classify extrasystemic and interstate armed conflicts as international in this analysis.

Descriptive statistics on the variables used in the empirical analysis are presented in Table 2. We have 331 conflicts between 1946 and 2005. The mean duration of a conflict is 5.46 years with a standard deviation of 8.05 years. Conflicts in the sample with the shortest duration are those that started and ended in the same year. We cannot differentiate between, say, a conflict which lasted 2 
months and one that lasted for 11 months. The dataset gives us start dates but not end dates. The conflict with the longest duration lasted for 56 years.

Table 3 presents the geographic distribution of conflicts. Of the 331 conflicts 101 are in Asia, 43 are in Latin America, 111 are in Africa and 39 in the Middle East. 108 conflicts have start dates prior to 1990. Asia and Africa stand out as conflict prone regions. Conflicts in Africa tend to be largely intrastate in nature. Asia stands out with the number of international conflicts.

\section{Results}

We compare the estimation results for the two data sets in Table 5.

Duration is measured by the number of years. Estimation results are largely in agreement further confirming that the two datasets reflect similar realities even though definitions and classification strata are different. Conflicts in the globalization era are shorter just as international conflicts tend to be shorter than intrastate conflicts. Coefficient estimates are quite similar as well. Estimation results based on the PRIO dataset, indicate regional differences where conflicts in Asia and the Middle East are longer.

In Table 6, duration models based on the Weibull distribution are presented for duration of conflicts for two alternative measures of duration. The coefficient estimates are presented in log relative-hazard form. The similarity between the models for two different measures of duration demonstrates that the choice of measure of duration does not matter.

In the period of globalization, the duration of conflicts is significantly different from before. When we use the number of deaths to measure duration, the hazard ratio is 1.337 indicating that the probability that a conflict will end is 1.337 
times more likely after 1990 than before. Therefore, conflicts after 1990 result in fewer deaths. When duration is measured by number of years, hazard ratio is 1.603. Along the same lines, the duration of international conflicts is also significantly different from the duration of domestic conflicts. International conflicts have a hazard ratio of 1.455 when number of deaths is used as a duration measure and 2.029 when the more conventional measure of duration is adopted, again indicating a shorter survival time for international conflicts. Conflicts stemming from ethnic differences do not have a survival time different from conflicts devoid of ethnic motives when we look at the number of deaths but based on the number of years we conclude that ethnic conflicts last longer. Finally, we investigated the duration of conflicts in different geographies and concluded that the duration of conflicts is not related to location when we look at the life of a conflict in years. However, number of deaths suggests that conflicts in Asia have a statistically significantly longer survival time, that is, are more deadly.

Even though the results are largely in agreement as one should expect since conflicts in the world would be catalogued by and large similarly, it is still comforting for empirical researchers to see that relatively minor differences in definitions do not affect broad conclusions. However, differences exist which necessitate caution in interpreting results. Note that the CSP dataset does not indicate regional differences while the PRIO dataset does, when the number of years is used as a measure of duration. But the CSP dataset also finds a regional effect when duration based on number of deaths is investigated. 


\section{Conclusion}

In this paper, we analyzed the determinants of duration of conflicts. The wellknown conflict database of International Peace Research Institute was compared with the database of Center for Systemic Peace which included data on the number of deaths in addition to length of conflict. The number and distribution of conflicts show some variation however duration analysis yields results that are robust over datasets. International conflicts and conflicts in the globalization era are found to have a shorter life. Conflicts in Asia last longer.

\section{REFERENCES}

Addison, T and M. Murshed. 2005. Transnational terrorism as a spillover of domestic disputes in other countries. Defense and Peace Economics, 16: 69-82.

Alesina, A., E. Spolaore and R. Wacziarg. 2000. Economic integration and political disintegration. American Economic Review, 90(5) :1276-1296.

Alesina, A. and E. Spolaore. 1997. On the numbers and size of nations, Quarterly Journal of Economics. 112 :1027-1056.

Collier, P., A., Hoeffler and M. Soderbom. 2001. On the duration of civil wars, Policy Research Working Paper No:2681 The World Bank.

Easterly, W. 2000. Can institutions resolve ethnic conflict?, Policy Research Working Paper No:2482 The World Bank. 
Elbadawi, I. and N. Sambanis. 2000. External interventions and the duration of civil wars, Policy Research Working Paper No:2433 The World Bank.

Elbadawi, I. and N. Sambanis. 2001. How much war will we see? Policy Research Working Paper No:2533 The World Bank.

Ellingsen, T. 2000. Colorful community or ethnic witches' brew? Multiethnicity and domestic conflict during and after the Cold War. Journal of Conflict Resolution 44: 228-249.

Fearon, J. and L. David. 2001. Ethnicity, insurgency, and civil war. mimeo. Stanford University.

Khazanov, A. 2005. Ethnic and national conflicts in the age of globalization: Withering away, persistent, or domesticated. Totalitarian Movements and Political Religions 6: 271-286.

Krueger, A. and, J. Maleckova. 2002. Education, poverty, political violence and terrorism: Is there a causal connection? NBER Working Paper Series, No: 9074.

Li,Q. and D. Schaub. 2004. Economic globalization and transnational terrorism. Journal of Conflict Resolution 48: 230-258. 
Maddison, D. 2004. Increasing returns to information and the survival of Broadway theatre productions. Applied Economics Letters 11: 639-43.

Minier, A.J. 2003. Democrats, dictators, and demonstrators. Economic Inquiry 41: 224-233.

Mousseau,D.Y. 2001. Democratizing with ethnic divisions: A source of conflict? Journal of Peace Research 38: 547-567.

Reynol-Querol, M. 2005. Does democracy preempt civil wars? European Journal of Political Economy 21: 445-465.

Sambanis, N.1999. Ethnic partition as solution to ethnic war: An empirical critique of the theoretical literature. Policy Research Working Paper No:2208 The World Bank.

Sambanis, N.2002. A review of recent advances and future directions in the quantitave literature on civil war. Defence and Peace Economics 13(3):215-243.

Simonoff, J.and L.Ma. 2003. An empirical study of factors relating to the success of Broadway shows. Journal of Business 76:135-150.

Walls, W.D.1997. Increasing returns to information: some evidence from the Hong Kong movie market. Applied Economics Letters 4(5): 287-290. 
Walls,W.D. 1998. Product survival at the cinema: evidence from Hong Kong. Applied Economics Letters 5(4): 215-19. 
Table 1 - Descriptive Statistics: CSP

\begin{tabular}{|c|c|c|c|c|c|}
\hline Variable & Mean & $\begin{array}{l}\text { Std. } \\
\text { Dev. }\end{array}$ & Min. & Max. & Description \\
\hline DEATH & 90922 & 273607 & 200 & 2000000 & $\begin{array}{l}\text { Duration of conflict } \\
\text { measured as number } \\
\text { of deaths }\end{array}$ \\
\hline DURATION & 5.84 & 8.67 & 0 & 56 & $\begin{array}{l}\text { Duration of conflict } \\
\text { measured as number } \\
\text { of years }\end{array}$ \\
\hline GLOBAL & 0.26 & 0.44 & 0 & 1 & $\begin{array}{l}1 \text { if the conflict } \\
\text { started after } 1990,0 \\
\text { otherwise }\end{array}$ \\
\hline INTERNATIONAL & 0.18 & 0.39 & 0 & 1 & $\begin{array}{l}1 \text { if the conflict is } \\
\text { classified as } \\
\text { international violence } \\
\text { or war as classified } \\
\text { by CSP*, } 0 \text { otherwise }\end{array}$ \\
\hline ETHNIC & 0.33 & 0.47 & 0 & 1 & $\begin{array}{l}1 \text { if the conflict is } \\
\text { classified as ethnic } \\
\text { violence or ethnic } \\
\text { war by CSP, } 0 \\
\text { otherwise }\end{array}$ \\
\hline WAR & 0.41 & 0.49 & 0 & 1 & $\begin{array}{l}1 \text { if the conflict is } \\
\text { classified as ethnic, } \\
\text { civil or international } \\
\text { war as classified by } \\
\text { CSP, } 0 \text { otherwise }\end{array}$ \\
\hline LATIN & 0.11 & 0.32 & 0 & 1 & $\begin{array}{l}1 \text { if the conflict is in } \\
\text { Latin America, } 0 \\
\text { otherwise }\end{array}$ \\
\hline MIDEAST & 0.16 & 0.37 & 0 & 1 & $\begin{array}{l}1 \text { if the conflict is in } \\
\text { the Middle East, } 0 \\
\text { otherwise }\end{array}$ \\
\hline AFRICA & 0.29 & 0.46 & 0 & 1 & $\begin{array}{l}1 \text { if the conflict is in } \\
\text { Africa, } 0 \text { otherwise }\end{array}$ \\
\hline ASIA & 0.32 & 0.47 & 0 & 1 & $\begin{array}{l}1 \text { if the conflict is in } \\
\text { Asia, } 0 \text { otherwise }\end{array}$ \\
\hline
\end{tabular}

* Center for Systemic Peace 
Table 2. Descriptive Statistics: PRIO

\begin{tabular}{lrrrrl}
\hline \multicolumn{2}{l}{ Variable Mean Std. Min Max } & Description \\
& \multicolumn{3}{c}{ Dev. } & &
\end{tabular}


Table 3. Geographic Distribution of Conflicts

\begin{tabular}{|l|l|l|l|l|}
\hline & \multicolumn{2}{|l|}{ Intrastate } & \multicolumn{2}{l|}{ International } \\
\hline & CSP & PRIO & CSP & PRIO \\
\hline Latin America & 26 & 37 & 5 & 6 \\
\hline Africa & 63 & 103 & 14 & 8 \\
\hline Middle East & 27 & 29 & 17 & 10 \\
\hline Asia & 67 & 83 & 20 & 18 \\
\hline Other & 25 & 34 & 7 & 3 \\
\hline Total & 208 & 286 & 63 & 45 \\
\hline
\end{tabular}

Table : Geographic Distribution of Conflicts (CSP:1945-2005, PRIO:1946-2004)

Table 4. Distribution of Conflicts Over Time

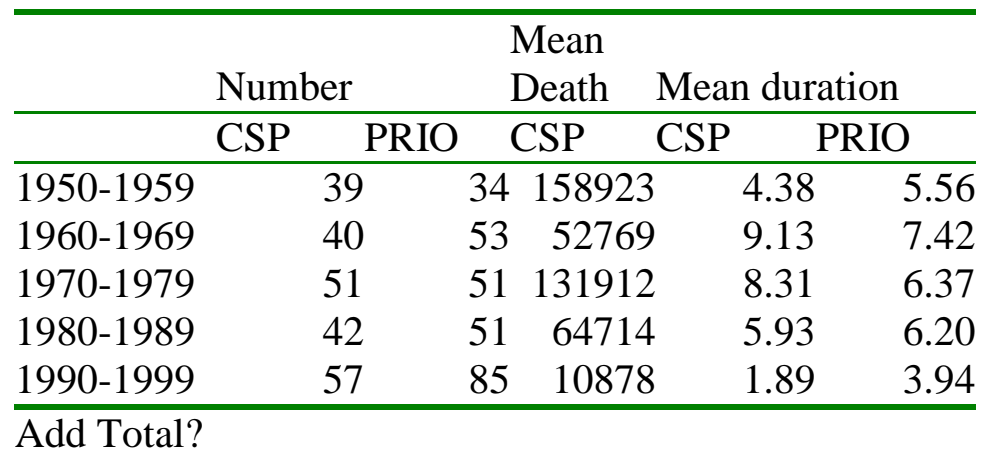


Table 5. Models of Conflict Duration as Measured by Number of Years Dependent Variable: Number of years

\begin{tabular}{|l|l|l|}
\hline & \multicolumn{2}{|c|}{ Hazard Ratio (std dev) $)^{\mathrm{a}}$} \\
\hline Variable & PRIO & CSP \\
\hline GLOBAL & $1.329 * *$ & $1.520 * * *$ \\
& $(0.182)$ & $(0.238)$ \\
\hline INTERNATIONAL & $2.734 * *$ & $2.581 * * *$ \\
& $(0.473)$ & $(0.461)$ \\
\hline MIDEAST & $0.450 * * *$ & 1.033 \\
& $(0.112)$ & $(0.250)$ \\
\hline LATIN & 0.827 & 1.441 \\
& $(0.197)$ & $(0.384)$ \\
\hline AFRICA & 0.600 & 1.018 \\
& $(0.119)$ & $(0.228)$ \\
\hline ASIA & $0.348 * * *$ & 0.899 \\
& $(0.073)$ & $(0.196)$ \\
\hline Log $(1 / \sigma)$ & $-0.088^{*} * *$ & $-0.118 * *$ \\
& $(0.043)$ & $(0.049)$ \\
\hline LR test & $\chi^{2}(6)=60.17$ & $\chi^{2}(6)=33.37$ \\
\hline Log L & -517.625 & -434.600 \\
\hline \# of Obs. & 331 & 269 \\
\hline \# of Censored & 30 & 22 \\
Observations & & \\
\hline
\end{tabular}

${ }^{\mathrm{a}}$ Coefficients are presented in log relative hazard form

* significant at $10 \%$

** significant at $5 \%$

*** significant at $1 \%$ 
Table 6. Models of Conflict Duration - Alternative Measures

\begin{tabular}{|l|l|l|}
\hline Variable & \multicolumn{2}{|c|}{ Hazard Ratio (std dev) ${ }^{\mathrm{a}}$} \\
\hline Dependent Variable & \# of deaths & \# of years \\
\hline GLOBAL & $1.337^{*}$ & $1.603^{* * *}$ \\
& $(0.215)$ & $(0.251)$ \\
\hline INTERNATIONAL & $1.455^{* *}$ & $2.029 * * *$ \\
& $(0.276)$ & $(0.383)$ \\
\hline ETHNIC & 0.980 & $0.599 * * *$ \\
& $(0.149)$ & $(0.091)$ \\
\hline MIDEAST & 0.932 & 0.940 \\
& $(0.233)$ & $(0.230)$ \\
\hline LATIN & 1.411 & 1.154 \\
& $(0.397)$ & $(0.318)$ \\
\hline AFRICA & 0.700 & 0.878 \\
& $(0.160)$ & $(0.202)$ \\
\hline ASIA & $0.630^{* *}$ & 0.836 \\
& $(0.147)$ & $(0.184)$ \\
\hline Log(1/ $\sigma)$ & $-0.730^{* * *}$ & $-0.096^{* *}$ \\
& $(0.046)$ & $(0.049)$ \\
\hline LR test & $\chi^{2}(7)=25.33$ & $\chi^{2}(7)=45.00$ \\
\hline Log L & -572.280 & -428.785 \\
\hline \# of Obs. & 269 & 269 \\
\hline \# of Censored & 22 & 22 \\
Observations & & \\
\hline
\end{tabular}

${ }^{\mathrm{a} C o e f f i c i e n t s ~ a r e ~ p r e s e n t e d ~ i n ~ l o g ~ r e l a t i v e ~ h a z a r d ~ f o r m ~}$

* significant at $10 \%$

$* *$ significant at $5 \%$

$* * *$ significant at $1 \%$ 